$1-1-1955$

\title{
The effect of heredity and environment on keel deformities in white leghorns
}

H. M. Hyre

Follow this and additional works at: https://researchrepository.wvu.edu/ wv_agricultural_and_forestry_experiment_station_bulletins

\section{Digital Commons Citation}

Hyre, H. M., "The effect of heredity and environment on keel deformities in white leghorns" (1955). West Virginia Agricultural and Forestry Experiment Station Bulletins. 381.

https://researchrepository.wvu.edu/wv_agricultural_and_forestry_experiment_station_bulletins/372 @ WVU. It has been accepted for inclusion in West Virginia Agricultural and Forestry Experiment Station Bulletins by an authorized administrator of The Research Repository @ WVU. For more information, please contact ian.harmon@mail.wvu.edu. 

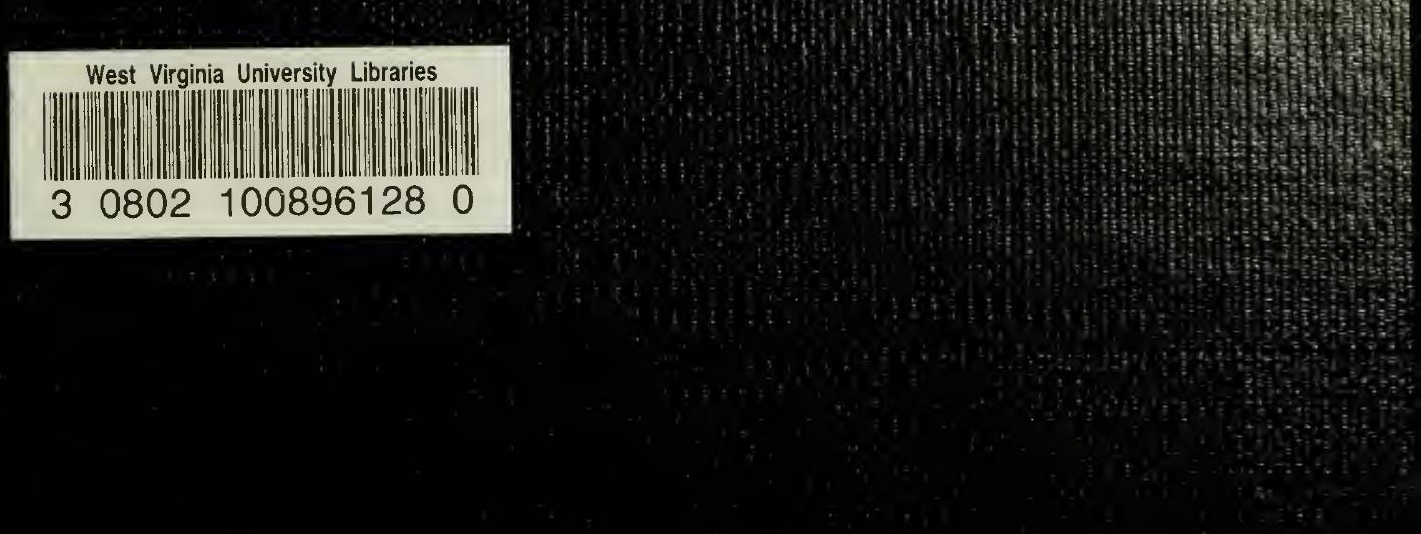
Digitized by the Internet Archive in 2010 with funding from

Lyrasis Members and Sloan Foundation 


\section{BULLETIN 381}

October 1955

\section{The Effect of Heredity and Environment on Keel Deformities in White Leghorns}
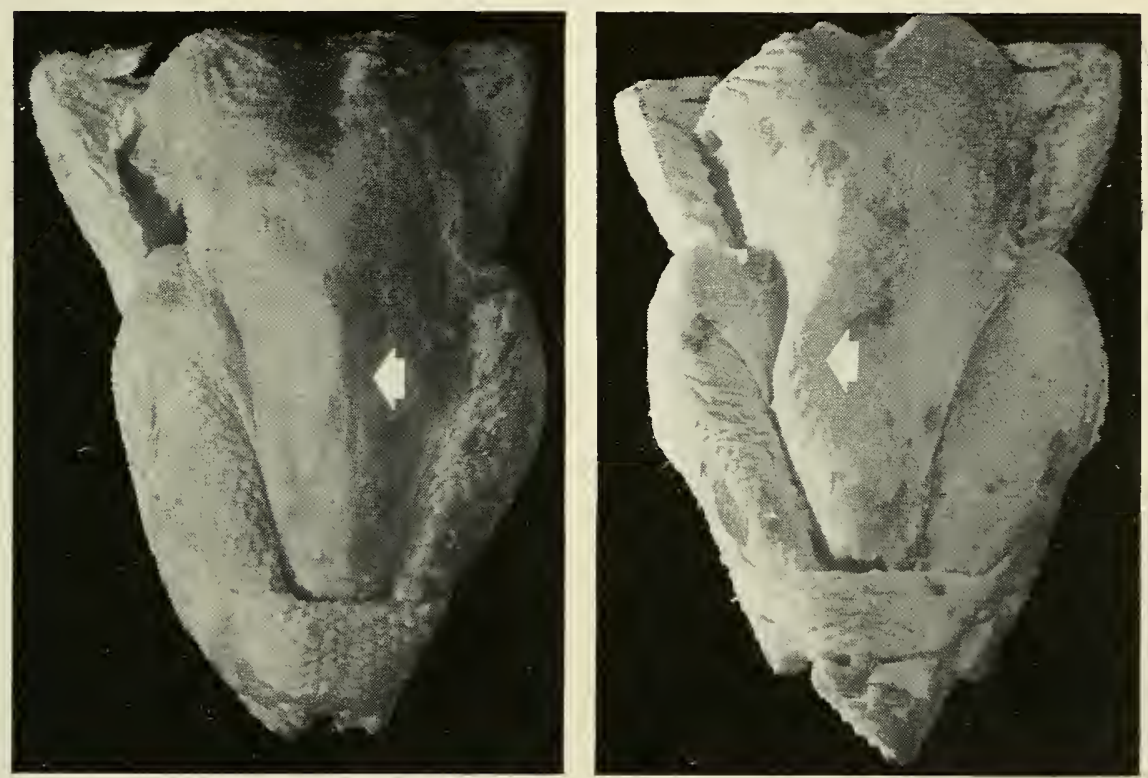

In recent years, factors infiuencing the market quality of poultry have been given more and more attention. With this interest in mind, the straightness of the keel becomes increasingly important. The carcass on the right above would not bring the highest market price, because buyers discriminate against both live and dressed birds with deformed keels. 


\section{Summary}

For this work the White Leghorn flock of the West Virginia University Agricultural Experiment Station was divided into two lines. One line was selected for normal keels and the other line was selected for deformed keels.

The tendency for deformed keels in chickens is inherited; however, this tendency cannot express itself unless the chicks have access to perches.

After six years of selective breeding for and against deformed keels in growing chickens, the abnormality in the normal-keel line was reduced from 21.06 per cent to 9.57 per cent at 10 weeks of age, and increased from 14.61 per cent to 47.68 per cent in the deformed-keel line.

A small percentage of deformed keels developed on the range and in the laying house.

A higher percentage of males possessed deformed keels than did females at 10 weeks of age.

The difference in egg shell quality of the two lines was very small.

Egg production was similar for the two lines throughout the study, except for the last year when the normal-keel line showed a 10 per cent greater production than the deformed-keel line. This could be at least partly due to greater selection pressure for egg production during the last few years of the study on the normal-keel line.

West Virginia University

Agricultural Experiment Station

College of Agriculture, Forestry, and Home Economics

H. R. Varney, Director

MORGANTOWN 


\section{The Effect of Heredity and Environment on Keel Deformities in White Leghorns}

\section{Introduction}

HAROLD M. HYRE*

The thin blade-like bone set between the heavy breast muscles of a chicken is known as the breast bone or keel. In normal chickens the keel is straight, but in some it becomes deformed. These deformities occur as curves or dents.

In recent years factors that influence the market quality of poultry have been given more and more attention. With this increase in interest in meat quality, the straightness of the keel becomes very important since a high percentage of the meat is located in this section of the chicken's body. A deformed keel greatly affects the appearance of the carcass, and severe curves and dents will reduce the amount of breast meat produced. Buyers discriminate against both live and dressed birds with deformed keels, and chickens produced for meat must have straight keels to obtain the highest market price.

This is also true for egg breeds such as White Leghorns, since eventually they will be sent to market. Deformed keels occur in both heavy and light breeds, and seem to be more prevalent in some strains than others. Any information regarding the cause of these deformities will be of value to poultry producers. Previous studies have revealed valuable information regarding deformed keels in chickens.

Buckner, Insko, and Henry (1946) found that the sternum of the chicken is slower to calcify than the leg bones. The crooked keel is a symptom of a constitutional weakness which they believe is caused by some kind of faulty metabolism, but not necessarily a faulty calcification.

Warren (1937) found the tendency to develop crooked keels to be inherited, but the expression of the inherent qualities was found to be determined largely by early roosting conditions. He also found that the age at which the chickens started to roost and the sharpness of the perch influenced the expression of the heritable differences in the tendency to develop crooked keels.

Platt (1932) reported that chicks placed in battery cages at three weeks of age and without perches differed widely as to the incidence of crooked keels. Two lots without perches had no crooked keels, whereas three lots provided with perches showed 66, 64, and 44 per cent

*Associate Poultry Husbandman. 
of crooked keels at eight weeks of age. Platt (1933) also reported that the width of the perches was a factor influencing the incidence of crooked keels.

\section{The Experiments}

The White Leghorn flock at the West Virginia University Agricultural Experiment Station was used for this study. A major reason for using Leghorns was the high incidence of deformed keels, approximately 15 per cent, in this flock at the time the work started in 1949. There had been no regularity as to the kind and amount of perch space used during the brooding periods for the few years just prior to the time the study was started.

For the purpose of investigating the effect of heredity and environment on keel condition, two lines were developed. One line was selected for straight or normal keels and the other line for deformed keels.

Some information regarding keel condition in the flock had been recorded for several years prior to the beginning of this study. Birds from those families which possessed deformed keels were placed in the deformed-keel line and those from families possessing straight keels were placed in the normal-keel line. After the lines were established there was no shifting of birds from one line to the other. Any birds with deformed keels that appeared in the normal-keel line were discarded. In some cases entire families were discarded when the incidence was considered excessive. The same situation existed in the deformed-keel line. Occasionally, families with a high incidence of normal keels would appear in the deformed-keel line and these were always discarded and were not placed in the normal-keel line.

Three hatches were made each year. The first hatch came off about the first of March and the other two hatches at two-week intervals thereafter. Each hatch was divided into four lots for brooding, and chicks from each hen were divided equally among the four brooding pens. Two of the pens were provided with perches of seven-eights of an inch in width, whereas no perches were provided in the other two pens.

The chicks were examined for keel condition at ten weeks of age, at which time the pullets were moved to the range where all birds had access to two-inch perches in the range shelters. The pullets were again examined for keel condition at about six months of age when they were brought in from the range and placed in the laying quarters. A third examination was made at the end of the first laying year when the hens were about five hundred days of age. 
Due to a possible relationship between keel condition and egg shell thickness, the shell strength of the eggs produced by the two lines was determined for the last two years of the experiment by the specific gravity method. This method consists of dipping the eggs into brine solutions having a range of specific gravities from 1.058 to 1.102 at intervals of .004. Each egg was given the specific gravity of the lowest solution in which it would float.

\section{Results}

\section{THE EFFECT OF PERCH USE UPON KEEL CONDITION}

Half of the progeny from each hen had access to perches during the brooding period, and the other half was brooded without perches. At ten weeks of age all chicks were examined for keel condition, and deformed keels were found only among birds that had access to perches. The birds that did not have access to perches possessed normal straight keels. This finding is in agreement with those of Platt (1932) and Warren (1937).

\section{THE EFFECT OF SELECTIVE BREEDING ON KEEL CONDITION}

Table 1 gives the percentage of birds in each line that had deformed keels at ten weeks of age. In determining these percentages only those birds which had access to perches are involved, since those birds that did not use perches did not develop deformed keels. It will be noted that in the first year of the experiment the normal-keel line had a higher percentage of deformed keels than the deformed-keel line. A plausible explanation might be that the information available at the start was insufficient to permit better selection of the birds which were originally placed in the normal-keel line. Therefore, they possessed a tendency for deformed keels, but this quality was not apparent at the time of selection.

It can be observed from the table that there was a reduction of deformed keels in the normal-keel line from 21.06 per cent for the first year to 9.57 per cent for the sixth year. For the deformed-keel line there was an increase from 14.61 per cent to 47.68 per cent.

Table 1. Percentage of Chickens with Deformed Keels AT 10 WeEks of Age.

\begin{tabular}{|c|c|c|c|c|c|}
\hline \multirow{2}{*}{\multicolumn{2}{|c|}{ YEAR }} & \multicolumn{2}{|c|}{ Birds, Normal-Keel Line } & \multicolumn{2}{|c|}{ BIRDS, DEFORMED-KEEL I INE } \\
\hline & & NUMBER & Per Cent & NuMBER & Per Cent \\
\hline 1949 & ........ & 394 & 21.06 & 171 & 14.61 \\
\hline 1950 & .............. & 474 & 5.69 & 214 & 18.69 \\
\hline 1951 & $\cdots$ & 569 & 4.22 & 251 & 16.33 \\
\hline 1952 & ............. & 359 & 11.97 & 180 & 22.22 \\
\hline 1953 & . & 1014 & 8.28 & 492 & 25.81 \\
\hline 1954 & (.................... & 977 & 9.57 & 411 & 47.68 \\
\hline
\end{tabular}


Table 2 gives the percentage of deformed keels which developed while the pullets were on range. This table shows that after the first two years of the experiment, a greater percentage of deformed keels developed in the deformed-keel line than in the normal-keel line.

Table 2. Percentage of Pullets with Deforned Keels at Six Months of Age Which Did Not Possess Deformities at 10 Weeks of Age.

\begin{tabular}{|c|c|c|c|c|c|}
\hline & \multirow{2}{*}{ YEAR } & \multicolumn{2}{|c|}{ BIRDS, NORMaL-KEeL LINE } & \multicolumn{2}{|c|}{ BIRDS, DEFORMED-KEEL LINE } \\
\hline & & NuMber & Per Cent & Number & Per Cent \\
\hline 1949 & (n)................... & 406 & 4.68 & 139 & 5.76 \\
\hline 1950 & ............. & 311 & 8.04 & 137 & 7.30 \\
\hline 1951 & 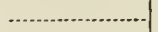 & 281 & 7.04 & 170 & 10.00 \\
\hline 1952 & (n..................... & 284 & 7.39 & 158 & 9.49 \\
\hline 1953 & (......................... & 282 & 6.73 & 126 & 11.11 \\
\hline
\end{tabular}

The hens were examined for keel condition at the end of the laying period when approximately five hundred days of age. Additional keel deformities occurred while the hens were in the laying house. There all birds had access to $2 \times 2$-inch perches. Table 3 show's the percentages of deformities that developed during the different years while the birds were in the laying pens.

Table 3. Percentage of Hens with Deforied Keels at 500 Days of Age Which Did Not Possess Deformities at 10 Weeks or at Six Mionths OF AGE.

\begin{tabular}{|c|c|c|c|c|c|}
\hline \multirow{2}{*}{\multicolumn{2}{|c|}{ YEAR }} & \multicolumn{2}{|c|}{ BIRDS, NORMaL-KEel LINE } & \multicolumn{2}{|c|}{ BIRDS, DEFORMED-KEEL LINE } \\
\hline & & NUMBER & Per Cent & Number & Per Cent \\
\hline 1949. & $\ldots$ & 369 & 2.98 & 125 & .80 \\
\hline 1950. & …….............. & 261 & 4.98 & 119 & 15.96 \\
\hline 1951 & ..................... & 246 & 3.25 & 129 & 6.20 \\
\hline 1952 . & . & 248 & 3.62 & 133 & 1.50 \\
\hline 1953 & 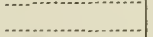 & 236 & 4.66 & 99 & 5.05 \\
\hline
\end{tabular}

\section{SEX DIFFERENCE IN KEEL DEFORMITIES}

A greater percentage of males developed deformed keels than did females. Table 4 shows the results for each sex for each year of the study. These results are in agreement with those of Warren (1937) who concluded that there is a slight sexual dimorphism with respect to the expression of crooked keels in chickens, with males showing the greater tendency. 
Table 4. Percentage of Males and Females with Deformed Keels AT 10 WeEKS OF Age.

\begin{tabular}{c|c|c|c|c}
\hline \multirow{2}{*}{ Year } & \multicolumn{2}{|c|}{ Malis } & \multicolumn{2}{c}{ Females } \\
\cline { 2 - 5 } & Number & Per CeNt & Number & Per Cent \\
\hline 1949 & 280 & 26.07 & 285 & 12.28 \\
1950 & 376 & 14.00 & 312 & 3.85 \\
1951 & 420 & 11.66 & 400 & 4.00 \\
1952 & 297 & 20.80 & 242 & 8.67 \\
1953 & 862 & 17.28 & 754 & 8.22 \\
1954 & 742 & 25.57 & 641 & 13.73 \\
\hline
\end{tabular}

Schroeder (1933) found a significant sexual dimorphism in the calcification of shaft bones in White Leghorn chicks at 10 weeks of age. He found males to have a lower rate of calcification of leg bones than females. It would seem that there might be a relationship between this lower rate of leg bone calcification in the males and the greater tendency for males to develop deformed keels.

\section{EGG PRODUCTION}

Egg production was recorded for the two lines. Table 5 gives the results in percentages for the various years. This is the percentage of production for the first nine months of lay, beginning with the first egg laid in the trap nest for each hen. An outbreak of Newcastle disease in 1950 and infectious bronchitis in 1951 are probably responsible for the lower production in these years. The higher production in the normal-keel line at the end of the experiment could be due, at least partly, to the greater selection pressure for egg production than was applied to the deformed-keel line.

Table 5. Pergentage of Egg Production-Hen-Housed Basis.

\begin{tabular}{l|c|c|c|c}
\hline \hline \multirow{2}{*}{ Year } & \multicolumn{2}{|c|}{ Hens, Normal-Keel LiNe } & \multicolumn{2}{c}{ Hens, Deformed-Keel Line } \\
\cline { 2 - 5 } & $\begin{array}{c}\text { Average } \\
\text { Number }\end{array}$ & Production & $\begin{array}{c}\text { Average } \\
\text { Number }\end{array}$ & Production \\
\hline 1949 & 433 & 71.35 & 142 & 66.66 \\
1950 & 317 & 55.03 & 143 & 51.21 \\
1951 & 284 & 54.76 & 176 & 54.76 \\
1952 & 294 & 59.09 & 166 & 59.06 \\
1953 & 303 & 66.57 & 157 & 56.70 \\
\hline
\end{tabular}

\section{SPECIFIC GRAVITY OF EGGS}

The first measurement of specific gravity was made in June, 1953, after the birds had been laying for approximately nine months. A second measurement was made in January the following year after the 
pullets had been laying about four months. It can be noted that eggs from hens in the normal-keel line had a slightly higher specific gravity than those produced by the deformed-keel line. The difference in January, 1954, of .0011 was statistically significant. The difference in June, 1953, of .0007 was not statistically significant.

Table 6. Average Specific Gravity of Eggs.

\begin{tabular}{|c|c|c|c|}
\hline YEAR & NormaL-KeEL LiNe & DEFORMED-KEEL LINE & DIFFERENCE \\
\hline $\begin{array}{l}\text { June, } 1953 \ldots \ldots . . . \\
\text { January, } 1954 \ldots . .\end{array}$ & $\begin{array}{l}1.0803 \\
1.0872\end{array}$ & $\begin{array}{l}1.0786 \\
1.0861\end{array}$ & $\begin{array}{l}.0007 \\
.0011\end{array}$ \\
\hline
\end{tabular}

\section{DISCUSSION}

Data gathered in this experiment agree with that of other studies in that deformed keels do not develop unless the birds use perches. It would seem that the tendency for deformed keels is inherited since it can be influenced by selection; however, the expression must be brought about by the use of perches.

Since deformed keels are caused by roosting, and most of this condition occurs during the first 10 weeks of age, it would seem advisable not to use perches during the brooding period. No harmful effects were observed when chicks were brooded without perches. In view of the fact that chickens produced for meat must have straight keels to demand the top market price, broilers should be grown without perches.

Chicks which are grown for egg production should also be grown without perches since eventually these birds will be sent to market. The results from this study show that deformed keels may occur during the growing period, and even to some extent after the birds have reached maturity. Individual bircls with deformed keels should not be used as breeders. When family records are available, it would be advisable to discard a family from the breeding flock when several of its members possess deformed keels.

\section{Literature Cited}

1. Buckner, G. Davis, W. M. Insko, Jr. and Amanda Harms Henry. 1946. Deformed Bones of Chickens. I. Crooked Keel. II. Osteopetrosis and Osteoma. Kentucky Agr. Exp. Sta. Bul. 492.

2. Platt, C. S. 1932. "Early Roosting As a Cause of Crooked Keels in Single Comb White Leghorn Cockerels." Abstract. Poultry Science, 11:362.

3. Platt, C. S. 1933. "Crooked Keels in Relation to Width of Perch." Abstract. Poultry Science, 12:333.

4. Schroeder, Carl H. 1933. "Sexual Differences in Calcification of Chicks and the Effect on Assays." Poultry Science, 12:256.

5. Warren, D. C. 1937. Physiologic and Genetic Studies of Crooked Keels in Chickens. Kansas Agr. Exp. Sta. Tech. Bul. 44. 



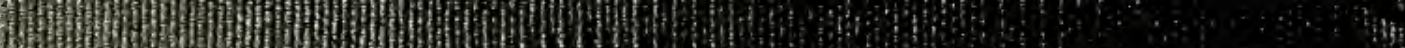

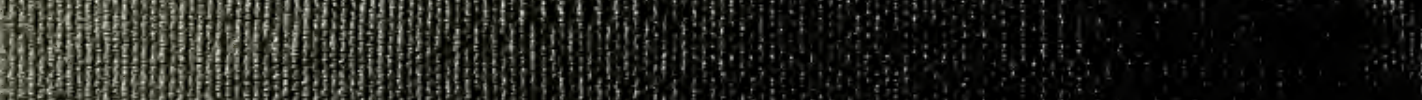
1.20

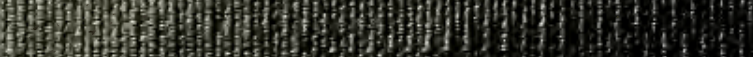

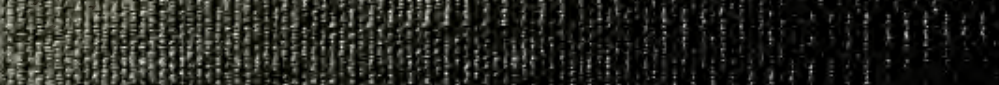

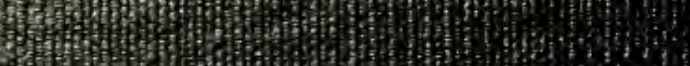

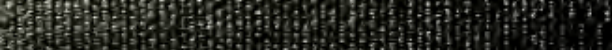

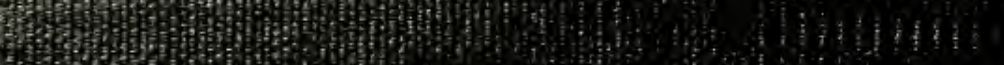

9

3.

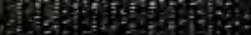

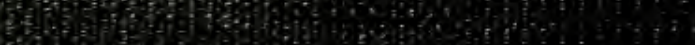

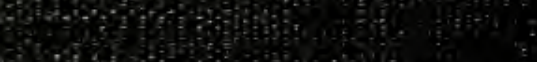

